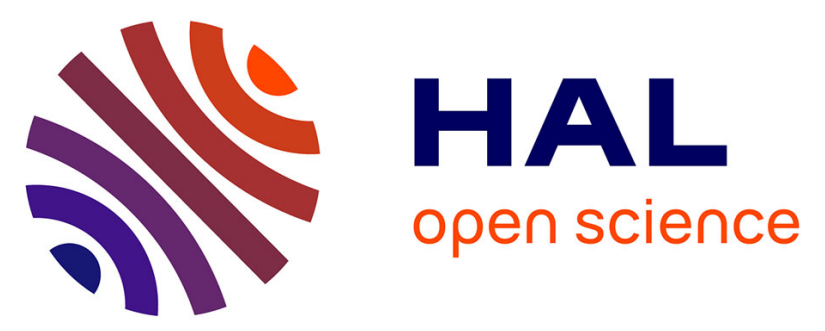

\title{
A probabilistic model of uncertainties in the substructures and interfaces of a dynamical system: application to the torsional vibration of a drill-string
} F. Real, F. Fontanela, T. G. Ritto, A. Batou, C. Desceliers

\section{- To cite this version:}

F. Real, F. Fontanela, T. G. Ritto, A. Batou, C. Desceliers. A probabilistic model of uncertainties in the substructures and interfaces of a dynamical system: application to the torsional vibration of a drill-string. Archive of Applied Mechanics, 2017, 87 (4), pp.685 - 698. 10.1007/s00419-016-1217-6 . hal-01657601

\author{
HAL Id: hal-01657601 \\ https://hal.science/hal-01657601
}

Submitted on 3 May 2018

HAL is a multi-disciplinary open access archive for the deposit and dissemination of scientific research documents, whether they are published or not. The documents may come from teaching and research institutions in France or abroad, or from public or private research centers.
L'archive ouverte pluridisciplinaire HAL, est destinée au dépôt et à la diffusion de documents scientifiques de niveau recherche, publiés ou non, émanant des établissements d'enseignement et de recherche français ou étrangers, des laboratoires publics ou privés. 


\title{
A probabilistic model of uncertainties in the substructures and interfaces of a dynamical system - application to the torsional vibration of a drill-string
}

Received: date / Accepted: date

\begin{abstract}
In this paper a new strategy for modeling uncertainties in the substructures and interfaces of a dynamical system is presented. This strategy is based on (1) the reduction of the dynamical model of each substructure using the Craig-Bampton method and (2) the use of the nonparametric probabilistic approach for the global modeling of uncertainties in each substructure. As an improvement with respect to existing nonparametric methods, the methodology proposed here constructs separated models of uncertainties for the inner and interface degrees of freedom, which allows to control separately the levels of fluctuation induced by these two sources of uncertainties. This methodology is applied for the analysis of the random vibration of a drill-string. Three strategies are compared: (1) a full nonparametric probabilistic approach on all the system, (2) the existing nonparametric probabilistic approach together with the Craig-Bampton substructuring method, and (3) the new nonparametric probabilistic approach proposed here with the separation of the inner and interface degrees of freedom uncertainties. It turns out that, for the same level of uncertainty, the three approaches give similar results but the new approach gives more flexibility for the control of the probabilistic model.
\end{abstract}

Keywords structural dynamics · stochastic dynamics · substructuring · Craig-Bampton Method · uncertainty quantification

\section{Introduction}

In the presence of uncertainties in a dynamical system, the probabilistic methods allow the assessment of the safety region for the quantities of interest. In this context, uncertainties in the parameters of the system can be

F. F. Real

National Metrology, Quality and Technology Institute-INMETRO, Rua da Estrela, 67, Rio de Janeiro, RJ, 20251-020, Brazil

E-mail: ffreal@inmetro.gov.br

F. Fontanela

Department of Mechanical Engineering - Federal University Santa Catarina, Trindade, Florianópolis, SC, 88040-900, Brazil

E-mail: ffontanela@gmail.com

T. G. Ritto

Department of Mechanical Engineering - Federal University of Rio de Janeiro, Ilha do Fundão, Rio de Janeiro, RJ, 21945-970, Brazil

E-mail: tritto@poli.ufrj.br

A. Batou

University of Liverpool, Centre for Engineering Dynamics, School of Engineering, L69 7ZF, United Kingdom

E-mail: anas.batou@liverpool.ac.uk.fr

C. Desceliers

Université Paris-Est, Laboratoire Modélisation et Simulation Multi Echelle, MSME UMR 8208 CNRS, 5 bd Descartes, 77454

Marn-la-Vallée, France

E-mail: christophe.desceliers@univ-pris-est.fr 
taken into account using a classical parametric probabilistic approach $[8 ; 23 ; 24]$, which consists in replacing the uncertain parameters by random variables. This method is very efficient if the computational model is a good representation of the dynamical systems. However, it has some limitations: (1) in case of numerous uncertain parameters, the identification of the hyperparameters related to the joint distribution of the random variable induces an intractable stochastic inverse problem; (2) by definition, this method is not capable to take into account uncertainties induced by modeling choices (constitutive laws, boundary conditions, etc).

The nonparametric probabilistic approach [25] is an attempt to overcome these limitations of the parametric probabilistic approach. In the nonparametric probabilistic approach, the uncertainties are taken into account globally at the operator level, by modeling the reduced-order matrices of a dynamical system as random matrices. The constructed stochastic model is controlled by a few number of dispersion parameters which make their experimental identification feasible $[1 ; 2 ; 5 ; 6 ; 7 ; 28]$. Furthermore, by randomizing the reduced-order operators, this approach allows to extend the range of prediction of the computational model without modifying the reduced displacement subspace.

The Craig-Bampton substructuring method $[4 ; 14]$ is a popular method used to develop a reduced-order model from a full finite element model by decomposing it into substructures. Soize and Chebli [26] combined the nonparameric probabilistic approach with the Craig-Bampton substructuring method and, for each substructure, a nonparametric model of uncertainties was introduced. The present paper extends the development of [26] proposing a new strategy, which combines (1) the nonparametric probabilistic approach, (2) the CraigBampton substructuring method, and (3) the separation of the inner and interface degrees of freedom (DOFs) uncertainties. The idea of separating the interface DOFs allows more flexibility for the stochastic model, which means that there is a specific parameter to control the uncertainties in the interface. An alternative approach has been addressed in [13], where the authors added an extra fictitious random coupling stiffness matrix. The approach proposed in the present paper uses the inner/interface DOFs decomposition introduced in the Craig-Bampton method directly.

This new method is applied to the linear torsional drill-string problem. The purpose of this application is that the drill-string is composed by (1) drillpipes (DP) and (2) the Bottom-Hole-Assembly (BHA). This two substructures might have different levels of uncertainties. The drill-string dynamics might be complex $[9 ; 11 ; 22 ; 30 ; 31 ; 15]$ and there are many sources of uncertainty in this problem. For instance, Spanos et al. [29] considered uncertainties in the lateral forces applied at the drill-bit. Ritto et al. [15] developed a nonparametric probabilistic approach to take into account model uncertainties in the bit-rock non-linear interaction model of a drill-string. In [16] the nonparametric probabilistic approach is employed to model uncertainties in the coupled axial-torsional drill-string dynamics. Other uncertainties aspects of the the drillstring problem were tackled in $[17 ; 18 ; 19 ; 20]$.

In this paper three nonparametric probabilistic strategies are presented and compared to: (1) a full nonparametric probabilistic approach on all the system [25], (2) the existing nonparametric probabilistic approach together with the Craig-Bampton substructuring method [26], and (3) the new nonparametric probabilistic approach proposed here with the separation of the inner and interface DOFs uncertainties.

The paper is organized as follows. In section 2, the deterministic finite element model and the CraigBampton substructuring method are presented. In section 3, the three strategies to model uncertainties are developed. The numerical results are presented in section 4 , and the concluding remarks are made in section 5 .

\section{Deterministic Model}

\subsection{Full finite element model}

As mentioned before, drill-strings are composed mainly by two substructures: DP and BHA. The DP are slender tubes that can reach kilometres, while the BHA is composed by thicker tubes (drill collars) together with the drill bit at the bottom and its length can reach thousands meters. Figure 1 shows a general scheme of a drill-string. In this paper, we are only interested in the steady-state small torsional vibration of the drillstring due to a torque applied at the bottom-end of the BHA. The inertial effects due to the global rotation of the drill-string and the gyroscopic effects induced by the transverse displacements (see [3]) are not taken into account here. The linear undamped torsional dynamics of a drill-string is descriped by the equation

$$
\rho I_{p} \frac{\partial^{2} \theta_{x}(x, t)}{\partial t^{2}}-G I_{p} \frac{\partial^{2} \theta_{x}(x, t)}{\partial x^{2}}=T(t),
$$




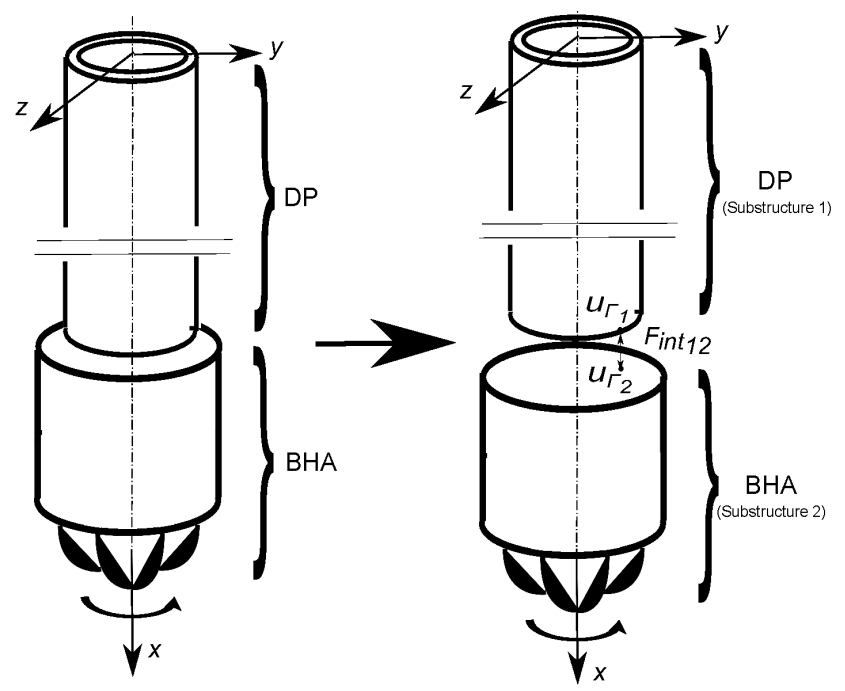

Fig. 1 General scheme of a drill-string.

where $\theta_{x}$ is the angular rotation about the $x$-axis (longitudinal axis), $I_{p}$ is the cross sectional polar moment of inertia, $G$ is the shear modulus, $T$ is the imposed torque per unit length. The above equation is discretized by means of the finite element method. After assembling the finite element matrices and adding a damping model, the vector $\mathbf{u}$ of the rotational DOFs is the solution in the frequency domain of the matrix equation

$$
\left(-\omega^{2}[M]+j \omega[C]+[K]\right) \mathbf{u}(\omega)=\mathbf{f}(\omega),
$$

where $\omega$ is the angular frequency, $\mathbf{f}$ is the external force vector, $j$ is the imaginary unit, while $[M],[C]$, and $[K]$ are the $n \times n$ mass, damping, and stiffness matrices, respectively.

\subsection{Reduced-order modeling using elastic modes}

In this section the full finite element model is reduced using the classical elastic modes. The $m$ first eigenvalues $0<\lambda_{1} \leq \lambda_{2} \leq \ldots \leq \lambda_{m}$ associated with the elastic modes $\left\{\phi_{1}, \phi_{2}, \ldots, \phi_{m}\right\}$ are solutions of the following generalized eigenvalue problem

$$
[K] \phi=\lambda[M] \phi .
$$

The reduced-order model is obtained by projecting the full computational model on the subspace spanned by the $m$ first elastic modes calculated using Eq. (3). Let $[\Phi]$ be the $n \times m$ matrix whose columns are the $m$ first elastic modes. We then introduce the approximation

$$
\mathbf{u}(\omega)=[\Phi] \mathbf{q}(\omega),
$$

in which $\mathbf{q}(\omega)$ is the vector of the $m$ generalized coordinates obtained from the following reduced matrix equation

$$
\left(-\omega^{2}[\tilde{M}]+j \omega[\widetilde{C}]+[\widetilde{K}]\right) \mathbf{q}(\omega)=\tilde{\mathbf{f}}(\omega),
$$

in which $[\widetilde{M}]=[\Phi]^{T}[M][\Phi],[\widetilde{C}]=[\Phi]^{T}[C][\Phi]$ and $[\widetilde{K}]=[\Phi]^{T}[K][\Phi]$ are the $m \times m$ mass, damping and stiffness generalized matrices, and where $\tilde{\mathbf{f}}(\omega)=[\Phi]^{T} \mathbf{f}(\omega) \in \mathbb{R}^{n}$ is the vector of the generalized forces.

\subsection{Craig-Bampton substructuring method}

It is assumed that the structure is decomposed into $n_{s}$ substructures $S_{1}, S_{2}, \ldots, S_{n_{s}}$. For instance, for the drillstring shown in the figure 1 , there are two substructures (DP + BHA). For $k=1, \ldots, n_{s}$, the displacement $\mathbf{u}_{k}$ 
of $S_{k}$ consists in $n_{\mathrm{I}, k}$ inner DOFs $\mathbf{u}_{k}^{\mathrm{I}}$ and in $n_{\Gamma, k}$ interface DOFs $\mathbf{u}_{k}^{\Gamma}$, i.e.,

$$
\mathbf{u}_{k}=\left(\begin{array}{c}
\mathbf{u}_{k}^{\mathrm{I}} \\
\mathbf{u}_{k}^{\Gamma}
\end{array}\right) .
$$

For $A=M, C$ or $K$, let $\left[A_{k}\right]$ be the mass, damping or stiffness matrix of substructure $S_{k}$ and let $\mathbf{f}_{k}$ be the force vector of substructure $S_{k}$. We then have

$$
\left[A_{k}\right]=\left(\begin{array}{c}
{\left[A_{k}^{\mathrm{II}}\right]\left[A_{k}^{\mathrm{I} \Gamma}\right]} \\
{\left[A_{k}^{\Gamma \mathrm{I}}\right]\left[A_{k}^{\Gamma \Gamma}\right]}
\end{array}\right) \quad \text { and } \quad \mathbf{f}_{k}=\left(\begin{array}{c}
\mathbf{f}_{k}^{\mathrm{I}} \\
\mathbf{f}_{k}^{\mathrm{c}}
\end{array}\right),
$$

in which $\mathbf{f}_{k}^{\mathrm{I}}$ is the inner force and $\mathbf{f}_{k}^{\mathrm{c}}$ is the coupling force at the interface. In Eq. (5), it is assumed that there is no external force applied on the interfaces. The Craig-Bampton substructuring method [4] consists in reducing the number of inner DOFs by using fixed-interface elastic and static modes such that

$$
\left(\begin{array}{c}
\mathbf{u}_{k}^{\mathrm{I}} \\
\mathbf{u}_{k}^{\Gamma}
\end{array}\right)=\left(\begin{array}{cc}
{\left[\Phi_{k}^{\mathrm{I}}\right]} & {\left[R_{k}^{\mathrm{I}}\right]} \\
{[0]} & {\left[\mathrm{I}_{\left.n_{\Gamma, \mathrm{k}}\right]}\right.}
\end{array}\right)\left(\begin{array}{c}
\mathbf{q}_{k}^{\mathrm{I}} \\
\mathbf{u}_{k}^{\Gamma}
\end{array}\right)
$$

where $\left[\Phi_{k}^{\mathrm{I}}\right]$ is the matrix of the $m_{k}$ fixed-interface elastic modes, $R_{k}^{\mathrm{I}}$ are the matrix of the static modes described such that $R_{k}^{\mathrm{I}}=-\left[K_{k}^{\mathrm{II}}\right]^{-1}\left[K_{k}^{\mathrm{I} \Gamma}\right]$ and $\left[I_{n_{\Gamma, k}}\right]$ is the $\left(n_{\Gamma, k} \times n_{\Gamma, k}\right)$ identity matrix. In Eq.(8), $\mathbf{q}_{k}^{\mathrm{I}}$ is the vector of the $m_{k}$ generalized coordinates related to the fixed-interface elastic modes. The Eq. (9) can be rewritten as

$$
\mathbf{u}_{k}=\left[\Psi_{k}\right] \mathbf{q}_{k}
$$

with

$$
\left[\Psi_{k}\right]=\left(\begin{array}{cc}
{\left[\Phi_{k}^{\mathrm{I}}\right]} & {\left[R_{k}^{\mathrm{I}}\right]} \\
{[0]} & {\left[I_{\left.n_{\Gamma, k}\right]}\right]}
\end{array}\right) \quad \text { and } \quad \mathbf{q}_{k}=\left(\begin{array}{c}
\mathbf{q}_{k}^{\mathrm{I}} \\
\mathbf{u}_{k}^{\Gamma}
\end{array}\right) .
$$

Let $n_{k}=m_{k}+n_{\Gamma, k}$. For $A=M, C$ or $K$, let $\left[\tilde{A}_{k}\right]$ be $\left(n_{k} \times n_{k}\right)$ such that

$$
\left[\tilde{A}_{k}\right]=\left[\Psi_{k}\right]^{T}\left[A_{k}\right]\left[\Psi_{k}\right]=\left(\begin{array}{c}
{\left[\tilde{A}_{k}^{\mathrm{II}}\right]\left[\tilde{A}_{k}^{\mathrm{I} \Gamma}\right]} \\
{\left[\tilde{A}_{k}^{\Gamma \mathrm{I}}\right]\left[\tilde{A}_{k}^{\Gamma \Gamma}\right]}
\end{array}\right) .
$$

Let $\left[P_{k}^{\mathrm{I}}\right]=\left(\left[I_{m_{k}}\right][0]\right)$ and $\left[P_{k}^{\Gamma}\right]=\left([0]\left[I_{n_{\Gamma, k}}\right]\right)$ be the projection matrices on the inner and interface coordinates, respectively. We then have

$$
\left[\tilde{A}_{k}^{\mathrm{II}}\right]=\left[P_{k}^{\mathrm{I}}\right]^{T}\left[\tilde{A}_{k}\right]\left[P_{k}^{\mathrm{I}}\right], \quad\left[\tilde{A}^{\Gamma \Gamma}\right]=\left[P_{k}^{\mathrm{I}}\right]^{T}\left[\tilde{A}_{k}\right]\left[P_{k}^{\Gamma}\right], \quad\left[\tilde{A}_{k}^{\Gamma \Gamma}\right]=\left[P_{k}^{\Gamma}\right]^{T}\left[\tilde{A}_{k}\right]\left[P_{k}^{\Gamma}\right],
$$

For the stiffness matrices, the coupling blocks are algebraically equal to zero. For readability, let assume that there are only $n_{s}=2$ substructures. Taking into account the continuity of the displacement at the interface, the force equilibrium at the interface and the relation Eq. (9) for each substructure, the dynamical matrix equation of the assembled structure for the substructuring Craig-Bampton method are written with lower subscript CB as follow

$$
\left(-\omega^{2}\left[M_{\mathrm{CB}}\right]+j \omega\left[C_{\mathrm{CB}}\right]+\left[K_{\mathrm{CB}}\right]\right) \mathbf{q}_{\mathrm{CB}}=\mathbf{f}_{\mathrm{CB}}
$$

in which

$$
\mathbf{q}_{\mathrm{CB}}=\left(\begin{array}{c}
\mathbf{q}_{1}^{\mathrm{I}} \\
\mathbf{q}_{2}^{\mathrm{I}} \\
\mathbf{u}^{\mathrm{I}}
\end{array}\right) \quad, \quad \mathbf{f}_{\mathrm{CB}}=\left(\begin{array}{c}
{\left[\Psi_{1}\right]^{T} \mathbf{f}_{1}^{\mathrm{I}}} \\
{\left[\Psi_{2}\right]^{T} \mathbf{f}_{2}^{\mathrm{I}}} \\
{\left[R_{1}^{\mathrm{I}}\right]^{T} \mathbf{f}_{1}^{\mathrm{I}}+\left[R_{2}^{\mathrm{I}}\right]^{T} \mathbf{f}_{2}^{\mathrm{I}}}
\end{array}\right),
$$


and where for $A=M, C$ or $K$,

$$
\left[A_{\mathrm{CB}}\right]=\left(\begin{array}{ccc}
{\left[\tilde{A}_{1}^{\mathrm{II}}\right]} & {[0]} & {\left[\tilde{A}_{1}^{\mathrm{I \Gamma}}\right]} \\
{[0]} & {\left[\tilde{A}_{2}^{\mathrm{II}}\right]} & {\left[\tilde{A}_{2}^{\mathrm{I \Gamma}}\right]} \\
{\left[\tilde{A}_{1}^{\Gamma \mathrm{I}}\right]} & {\left[\tilde{A}_{2}^{\Gamma \mathrm{I}}\right]} & {\left[\tilde{A}_{1}^{\Gamma \Gamma}\right]+\left[\tilde{A}_{2}^{\Gamma \Gamma}\right]}
\end{array}\right)
$$

The displacement vector $\mathbf{u}(\omega)$ is finally calculated as

$$
\mathbf{u}(\omega)=[\Psi] \mathbf{q}_{\mathrm{CB}}(\omega),
$$

where $[\Psi]$ is constructed by assembling matrices $\left[\Psi_{1}\right], \ldots,\left[\Psi_{n_{s}}\right]$.

\section{Contruction of the Stochastic Models}

3.1 Brief overview of the nonparametric probabilistic formulation for random matrices

The nonparametric probabilistic approach [25] is based on the random matrix theory [12]. It consists in replacing the deterministic reduced-order matrices of the deterministic computational model by random matrices. Thus, it acts directly at the reduced operator level. It is assumed that there are no rigid body modes and consequently the deterministic reduced matrices are symmetric positive-definite. This approach consists in replacing any deterministic matrix $[A]$ of the computational model by a random matrix $[\mathbf{A}]$ which is written as

$$
[\mathbf{A}]=\left[L_{A}\right]\left[\mathbf{G}_{A}\right]\left[L_{A}\right]^{T},
$$

where $\left[\mathbf{G}_{A}\right]$ is a normalized random matrix and $\left[L_{A}\right]$ is a lower triangular matrix related to the Cholesky factorization of matrix $[\widetilde{A}]$, i.e.,

$$
[A]=\left[L_{A}\right]\left[L_{A}\right]^{T}
$$

The probability density function of random matrix $\left[\mathbf{G}_{A}\right]$ is constructed using the maximum entropy principle [10] and depends on a dispersion parameter $\delta_{A}$, which controls the level of the statistical fluctuations of the random matrix $\left[\mathbf{G}_{A}\right]$ around its mean value that is the unit matrix $\left[I_{m}\right]$. We then have

$$
\delta_{A}=\left(\frac{E\left\{\left\|\left[\mathbf{G}_{A}\right]-\left[I_{m}\right]\right\|_{F}^{2}\right\}}{\left\|\left[I_{m}\right]\right\|^{2}}\right)^{1 / 2}
$$

where $\|\cdot\|_{F}$ is the Frobenius norm and $E\{\cdot\}$ is the mathematical expectation. A generator of independent realizations of random matrix $\left[\mathbf{G}_{A}\right]$ has been proposed in [25].

3.2 Stochastic model $\mathrm{SM}_{\text {full }}$ : Nonparametric probabilistic approach for the reduced order computational model without substructuring method

The stochastic model $\mathrm{SM}_{\text {full }}$ is constructed in replacing each deterministic matrices $[M],[C]$ and $[K]$ in Eq. (5) by random matrices $[\mathbf{M}],[\mathbf{C}]$ and $[\mathbf{K}]$. We then have

$$
\left(-\omega^{2}[\mathbf{M}]+j \omega[\mathbf{C}]+[\mathbf{K}]\right) \mathbf{Q}=\tilde{\mathbf{f}}
$$

For $\mathbf{A}=\mathbf{M}, \mathbf{C}$ or $\mathbf{K}$, the probabilistic model of the random reduced-order matrix $[\mathbf{A}]$ is constructed by using the nonparametric probabilistic approach that is briefly presented in section 3.1. Hence, the stochastic model $\mathrm{SM}_{\text {full }}$ is completely defined by three dispersion coefficients $\delta_{M}, \delta_{C}, \delta_{K}$. 
3.3 Stochastic model $\mathrm{SM}_{\mathrm{CB} 1}$ : Nonparametric formulation of uncertainties for each substructure

In [26], a probabilistic model for taking into account different levels of uncertainties in each substructure has been proposed. For each substructure $S_{k}$, the reduced random mass, damping, and stiffness matrices were replaced by random matrices whose probabilistic models were constructed by using the nonparametric probabilistic approach that has been briefly presented in section 3.1. Hence, for $A=M, C$ or $K$ and for each substructure $S_{k}$, deterministic matrices $\left[\tilde{A}_{k}^{\mathrm{II}}\right],\left[\tilde{A}_{k}^{\Gamma \mathrm{I}}\right],\left[\tilde{A}_{k}^{\Gamma \Gamma}\right]$ introduced in section 2.3 and involved in the assembling of the deterministic matrix $\left[A_{\mathrm{CB}}\right]$, are replaced by the random matrices $\left[\tilde{\mathbf{A}}_{k}^{\mathrm{II}}\right],\left[\tilde{\mathbf{A}}_{k}^{\Gamma \mathrm{I}}\right]$ and $\left[\tilde{\mathbf{A}}_{k}^{\Gamma \Gamma}\right]$ defined as

$$
\left[\tilde{\mathbf{A}}_{k}^{\mathrm{II}}\right]=\left[P_{k}^{\mathrm{I}}\right]^{T}\left[\tilde{\mathbf{A}}_{k}\right]\left[P_{k}^{\mathrm{I}}\right], \quad\left[\tilde{\mathbf{A}}^{\mathrm{I} \Gamma}\right]=\left[P_{k}^{\mathrm{I}}\right]^{T}\left[\tilde{\mathbf{A}}_{k}\right]\left[P_{k}^{\Gamma}\right], \quad\left[\tilde{\mathbf{A}}_{k}^{\Gamma \Gamma}\right]=\left[P_{k}^{\Gamma}\right]^{T}\left[\tilde{\mathbf{A}}_{k}\right]\left[P_{k}^{\Gamma}\right],
$$

where $\left[\tilde{\mathbf{A}}_{k}\right]$ is a random matrix that statistical fluctuation due to the uncertainties related to $\left[\tilde{A}_{k}\right]$ (see section 2.3), and whose probabilistic model is constructed by using the nonparametric approach that is briefly presented in section 3.1. The assembling of those random matrices yield a random matrix $\left[\mathbf{A}_{\mathrm{CB} 1}\right]$ that models the statistical fluctuation related to uncertainties on $\left[A_{\mathrm{CB}}\right]$. For instance, for $n_{s}=2$, and for $\mathbf{A}=\mathbf{M}, \mathbf{C}$ or $\mathbf{K}$, we obtain

$$
\left[\mathbf{A}_{\mathrm{CB} 1}\right]=\left(\begin{array}{ccc}
{\left[\tilde{\mathbf{A}}_{1}^{\mathrm{II}}\right]} & {[0]} & {\left[\tilde{\mathbf{A}}_{1}^{\Gamma \Gamma}\right]} \\
{[0]} & {\left[\tilde{\mathbf{A}}_{2}^{\mathrm{II}}\right]} & {\left[\tilde{\mathbf{A}}_{2}^{\mathrm{I \Gamma}}\right]} \\
{\left[\tilde{\mathbf{A}}_{1}^{\Gamma \mathrm{I}}\right]} & {\left[\tilde{\mathbf{A}}_{2}^{\Gamma \mathrm{I}}\right]} & {\left[\tilde{\mathbf{A}}_{1}^{\Gamma \Gamma}\right]+\left[\tilde{\mathbf{A}}_{2}^{\Gamma \Gamma}\right]}
\end{array}\right)
$$

The stochastic model $\mathrm{SM}_{\mathrm{CB} 1}$ allows different levels of uncertainties to be modeled in each substructure and here are $3 \times n_{s}$ parameters which control the uncertainties of the system: $\delta_{M, 1}, \delta_{C, 1}, \delta_{K, 1}, \ldots, \delta_{M, n_{s}}, \delta_{C, n_{s}}, \delta_{K, n_{s}}$.

3.4 New stochastic model $\mathrm{SM}_{\mathrm{CB} 2}$ : Nonparametric formulation of uncertainties for each substructure with separation of the statistical fluctuations related to the inner and interface DOFs

In stochastic model $\mathrm{SM}_{\mathrm{CB} 1}$, for each substructure, every components of a given random matrix $\left[\tilde{\mathbf{A}}_{k}\right]$ with $\mathbf{A}=\mathbf{M}, \mathbf{C}$ or $\mathbf{K}$ is related to the same dispersion coefficient. Nevertheless, each component of random matrice $\left[\tilde{\mathbf{A}}_{k}\right]$ is involved in a linear system of stochastic second order ordinary differential equations in terms of random generalized coordinates and random displacements on the interfaces between two substructures. The stochastic model $\mathrm{SM}_{\mathrm{CB} 1}$ does not allow to take into account different levels of statistical fluctuation on those coefficients. In order to circumvent such a limitation, a new stochastic model $\mathrm{SM}_{\mathrm{CB} 2}$ is proposed in the present paper. For each substructure $S_{k}$ and for $\mathbf{A}=\mathbf{M}, \mathbf{C}$ or $\mathbf{K}$, two statistically independent random matrices $\left[\tilde{\mathbf{A}}_{k}^{\mathrm{I}}\right]$ and $\left[\tilde{\mathbf{A}}_{k}^{\Gamma}\right]$ are introduced to model the statistical fluctuations that are related to each matrix $\left[\tilde{A}_{k}^{\mathrm{I}}\right]$. Their probabilistic model is constructed using the nonparametric probabilistic approach that is briefly presented in section (3.1) and for two different dispersion cofficients $\delta_{A, \mathrm{I}, k}$ and $\delta_{A, \Gamma, k}$. The Cholesky factorisation of these random matrices yields two random lower triangular matrices $\left[\mathbf{L}_{A, k}^{\mathrm{I}}\right]$ and $\left[\mathbf{L}_{A, k}^{\Gamma}\right]$ such that

$$
\left[\tilde{\mathbf{A}}_{k}^{\mathrm{I}}\right]=\left[\mathbf{L}_{A, k}^{\mathrm{I}}\right]\left[\mathbf{L}_{A, k}^{\mathrm{I}}\right]^{T}, \quad\left[\tilde{\mathbf{A}}_{k}^{\Gamma}\right]=\left[\mathbf{L}_{A, k}^{\Gamma}\right]\left[\mathbf{L}_{A, k}^{\Gamma}\right]^{T} .
$$

Hence, for $A=M, C$ or $K$ and for each substructure $S_{k}$, deterministic matrices $\left[\tilde{A}_{k}^{I I}\right],\left[\tilde{A}_{k}^{\Gamma \Gamma}\right],\left[\tilde{A}_{k}^{\Gamma \Gamma}\right]$ introduced in section 2.3 and involved in the assembling of the deterministic matrix $\left[A_{\mathrm{CB}}\right]$, are replaced by the random matrices $\left[\tilde{\mathbb{A}}_{k}^{I I}\right],\left[\tilde{\mathbb{A}}_{k}^{\Gamma \Gamma}\right]$ and $\left[\tilde{\mathbb{A}}_{k}^{\Gamma \Gamma}\right]$ defined as

$$
\left[\tilde{\mathbb{A}}_{k}^{I I}\right]=\left[P_{k}^{I}\right]^{T}\left[\tilde{\mathbf{A}}_{k}^{I}\right]\left[P_{k}^{I}\right], \quad\left[\tilde{\mathbb{A}}_{k}^{I \Gamma}\right]=\left[P_{k}^{I}\right]^{T}\left[\tilde{\mathbf{L}}_{A, k}^{I}\right]\left[\mathbf{L}_{A, k}^{\Gamma}\right]^{T}\left[P_{k}^{\Gamma}\right], \text { and } \quad\left[\tilde{\mathbb{A}}_{k}^{\Gamma \Gamma}\right]=\left[P_{k}^{\Gamma}\right]^{T}\left[\tilde{\mathbf{A}}_{k}^{\Gamma}\right]\left[P_{k}^{\Gamma}\right] .
$$

The assembling of those random matrices yields a random matrix $\left[\mathbf{A}_{\mathrm{CB} 2}\right]$ that models the statistical fluctuation related to uncertainties on $\left[A_{\mathrm{CB} 2}\right]$. For instance, for $n_{s}=2$, and for $\mathbf{A}=\mathbf{M}, \mathbf{C}$ or $\mathbf{K}$, we have

$$
\left[\mathbf{A}_{\mathrm{CB} 2}\right]=\left(\begin{array}{ccc}
{\left[\tilde{\mathbb{A}}_{1}^{\mathrm{II}}\right]} & {[0]} & {\left[\tilde{\mathbb{A}}_{1}^{\Gamma \Gamma}\right]} \\
{[0]} & {\left[\tilde{\mathbb{A}}_{2}^{\mathrm{II}}\right]} & {\left[\tilde{\mathbb{A}}_{2}^{\mathrm{I}}\right]} \\
{\left[\tilde{\mathbb{A}}_{1}^{\Gamma \mathrm{I}}\right]} & {\left[\tilde{\mathbb{A}}_{2}^{\Gamma \mathrm{I}}\right]} & {\left[\tilde{\mathbb{A}}_{1}^{\Gamma \Gamma}\right]+\left[\tilde{\mathbb{A}}_{2}^{\Gamma \Gamma}\right]}
\end{array}\right)
$$


For $\mathbf{A}=\mathbf{M}, \mathbf{C}$ or $\mathbf{K}$, the levels of the statistical fluctuations of random matrix $\left[\mathbf{A}_{\mathrm{CB} 2}\right]$ is controlled by two dispersion coefficients $\delta_{A, \mathrm{I}, k}$ and $\delta_{A, \Gamma, k}$, which are related to the nonparametric models of $\left[\tilde{\mathbf{A}}_{k}^{\mathrm{I}}\right]$ and $\left[\tilde{\mathbf{A}}_{k}^{\Gamma}\right]$, respectively. Then, for each substructure, the probabilistic model of uncertainties is controlled by six dispersion coefficients, that allow controlling the level of statistical fluctuations of the inner and interface coordinates separately for each random matrices, giving more flexibility than the stochastic model $\mathrm{SM}_{\mathrm{CB} 1}$.

Finally, for the full structure, the probabilistic model of uncertainties is controlled by $6 \times n_{s}$ dispersion coefficients: $\delta_{M, \mathrm{I}, 1}, \delta_{M, \Gamma, 1}, \delta_{C, \mathrm{I}, 1}, \delta_{C, \Gamma, 1}, \delta_{K, \mathrm{I}, 1}, \delta_{K, \Gamma, 1}, \ldots, \delta_{M, \mathrm{I}, n_{s}}, \delta_{M, \Gamma, n_{s}}, \delta_{C, \mathrm{I}, n_{s}}, \delta_{C, \Gamma, n_{s}}, \delta_{K, \mathrm{I}, n_{s}}, \delta_{K, \Gamma, n_{s}}$.

\subsection{Presence of floating substructures}

Some of the substructures of the systems may not be attached to a fixed frame. This is the case, for instance, for the BHA of the drill-string shown in figure 1. These floating substructures present rigid body modes yielding a positive semi-definite stiffness matrix $\left[\tilde{K}_{k}\right]$ and then the nonparametric construction presented in the previous section cannot be applied directly. To circumvent this difficulty, the projection of the stiffness matrix into the rigid body subspace is kept equal to zero almost surely while the projection into the subspace of the flexible displacements are randomized. Such a construction makes sense since the rigid body subspace is not perturbed by the presence of uncertainties. The construction proposed here corresponds to the ensemble of random matrices $\mathrm{SE}^{+0}$ introduced in [27]. Let $\left[P_{\mathrm{rb}, k}\right]$ be the matrix whose columns are vectors that span the null space of $\left[\tilde{K}_{k}\right]$ and let $\left[P_{\text {flex }, k}\right]$ be the matrix whose columns are vectors that spans the range space of $\left[\tilde{K}_{k}\right]$. It is assumed that the columns of $\left[P_{\mathrm{rb}, k}\right]$ and $\left[P_{\mathrm{flex}, k}\right]$ are normalized. We then have $\left[P_{\mathrm{rb}, k}\right]^{T}\left[P_{\mathrm{flex}, k}\right]=[I]$. Let $\left[P_{k}\right]=\left(\left[P_{\mathrm{rb}, k}\right]\left[P_{\text {flex }, k}\right]\right)$, then

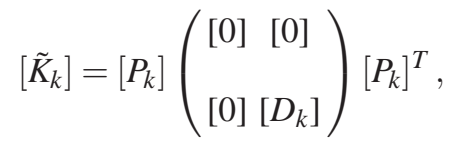

in which $\left[D_{k}\right]$ is the diagonal matrix of the nonzero eigenvalues of $\left[\tilde{K}_{k}\right]$. The stochastic models $\mathrm{SM}_{C B 1}$ and $\mathrm{SM}_{C B 2}$ are then constructed by replacing the deterministic matrix $\left[D_{k}\right]$ by the random matrix $\left[\mathbf{D}_{k}\right]$ for which the probabilistic model is constructed by using the nonparametric approach presented in section 3.1. Finally, for $\left[\mathbf{K}_{k}\right]=\left[\tilde{\mathbf{K}}_{k}\right]$ (for the stochastic model $\mathrm{SM}_{C B 1}$ ), $\left[\tilde{\mathbf{K}}_{k}^{\mathrm{I}}\right]$ and $\left[\tilde{\mathbf{K}}_{k}^{\Gamma}\right]$ (for Stochastic Model SM $\mathrm{SB}_{C B 2}$ ), we have

$$
\left[\mathbf{K}_{k}\right]=\left[P_{k}\right]\left(\begin{array}{cc}
{[0]} & {[0]} \\
{[0]} & {\left[\mathbf{D}_{k}\right]}
\end{array}\right)\left[P_{k}\right]^{T} .
$$

\section{Application}

There are many sources of uncertainties related to the computational model of the drill-string presented in section 2. First, concerning each substructure, some parameters such as the material properties, the geometry and not perfectly known or present some variabilities along the axial axis. Then, the linear torsional model used for each substructure is a very simple representation of the torsional vibration of the drill-string yielding some model-form uncertainties in the model. Finally, the modeling of the interfaces for the present model is very simple compared to complex mechanical real link between the DP and the BHA. For this reasons, a probabilistic model of uncertainties is implemented in order to quantify the sensitivity of the outputs with respect to these uncertainties. The new probabilistic model presented in the previous section allows to study this sensitivity efficiently.

In this section, the three stochastic models $\mathrm{SM}_{\mathrm{full}}, \mathrm{SM}_{\mathrm{CB} 1}$ and $\mathrm{SM}_{\mathrm{CB} 2}$, presented in section 3, are implemented in order to take into account the uncertainties related to the computational model of the drill-string presented in section 2 .

First, the stochastic model $\mathrm{SM}_{\mathrm{CB} 2}$ is compared with the stochastic models $\mathrm{SM}_{\text {full }}$ and $\mathrm{SM}_{\mathrm{CB} 1}$. Then, the stochastic model $\mathrm{SM}_{\mathrm{CB} 2}$ is analyzed in order to evaluate the impact of the different sources of uncertainties: DP versus BHA, mass versus damping versus stiffness, and inner versus interface DOFs. 


\subsection{Parameters of the model}

Concerning the DP, the shear modulus is $70 \mathrm{GPa}$, the mass density is $7850 \mathrm{~kg} / \mathrm{m}^{3}$, the length is $1800 \mathrm{~m}$, the inner radius is $0.0475 \mathrm{~m}$ and the outer radius is $0.060 \mathrm{~m}$. The mass and stiffness matrices for this substructure are constructed using 100 elements with linear shape functions. The top-end of the DP is clamped.

Concerning the BHA, the shear modulus is $70 \mathrm{GPa}$, the mass density is $7850 \mathrm{~kg} / \mathrm{m}^{3}$, the length is $200 \mathrm{~m}$, the inner radius is $0.0475 \mathrm{~m}$ and the outer radius is $0.075 \mathrm{~m}$. The mass and stiffness matrices for this substructure are constructed using 100 elements with linear shape functions. A unit torque is applied to the bottom-end of the BHA for all the frequency range of analysis. The top-end of the BHA is coupled with the bottom-end of the DP. Therefore, there is only one interface DOF. It should be noted that the applied torque here is not representative of the real bit-rock interaction torque. The objective here is just to validate and illustrate the proposed methodology using a simple torque model which allows to perform a comparison between the stochastic models.

The response (random rotation) is observed at three points: $\mathrm{P}_{\mathrm{obs}, 1}$, which corresponds to the first nonclamped node at the top of the DP, $\mathrm{P}_{\mathrm{obs} .2}$, which corresponds to the interface node, and $\mathrm{P}_{\mathrm{obs} .3}$, which corresponds to the bottom node of the BHA. The statistical envelope with probability level 0.95 is estimated using 2500 Monte Carlo simulations.

As stated before, only two substructures are considered in the analyses: DP and BHA. The Craig-Bampton projection matrices $\left[\Phi_{1}^{\mathrm{I}}\right]$ and $\left[\Phi_{2}^{\mathrm{I}}\right]$ are both constructed using the number of modes obtained after a convergence analysis: $m_{1}=m_{2}=25$ fixed-interface elastic modes. The reduced damping matrices $\left[\tilde{C}_{1}\right]$ and $\left[\tilde{C}_{2}\right]$ are both constructed using a Rayleigh model, i.e., $\left[\tilde{C}_{1}\right]=a_{1}\left[\tilde{M}_{1}\right]+b_{1}\left[\tilde{K}_{1}\right]$ and $\left[\tilde{C}_{2}\right]=a_{2}\left[\tilde{M}_{2}\right]+b_{2}\left[\tilde{K}_{2}\right]$ where $a_{1}$, $b_{1}, a_{2}$ and $b_{2}$ are calculated such that the damping ratios are 0.05 and 0.01 at frequencies $1 \mathrm{~Hz}$ and $10 \mathrm{~Hz}$ for each substructure, respectively.

\subsection{Comparison of the three stochastic models}

In this first analysis, all $\delta$ 's are set equal to 0.1 . For the full model, $\mathrm{SM}_{\text {full }}, \delta_{M}=\delta_{C}=\delta_{K}=0.1$. For model $\mathrm{SM}_{\mathrm{CB} 1}, \delta_{M, 1}=\delta_{M, 2}=\delta_{C, 1}=\delta_{C, 2}=\delta_{K, 1}=\delta_{K, 2}=0.1$. Finally, for model $\mathrm{SM}_{\mathrm{CB} 2}, \delta_{M, \mathrm{I}, 1}=\delta_{M, \Gamma, 1}=\delta_{M, \mathrm{I}, 2}=$ $\delta_{M, \Gamma, 2}=\delta_{C, \mathrm{I}, 1}=\delta_{C, \Gamma, 1}=\delta_{C, \mathrm{I}, 2}=\delta_{C, \Gamma, 2}=\delta_{K, \mathrm{I}, 1}=\delta_{K, \Gamma, 1}=\delta_{K, \mathrm{I}, 2}=\delta_{K, \Gamma, 2}=0.1$.

Figures 2,3 and 4 show the comparison of the statistical envelopes at the three observed points, of each stochastic model. The continuous lines represents $\mathrm{SM}_{\text {full }}$, the dashed lines $\mathrm{SM}_{\mathrm{CB} 1}$, and the dotted lines $\mathrm{SM}_{\mathrm{CB} 2}$.

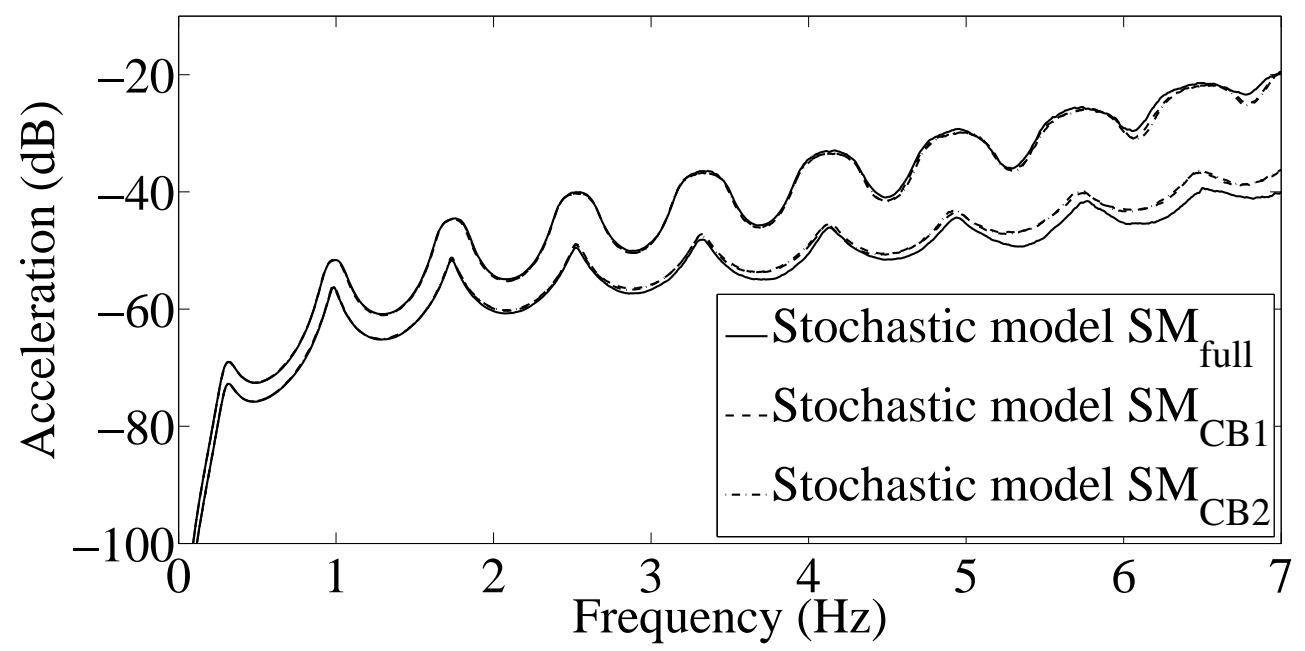

Fig. 2 Comparison of three stochastic models: Frequency response in acceleration for point $\mathrm{P}_{\mathrm{obs}, 1}$. 


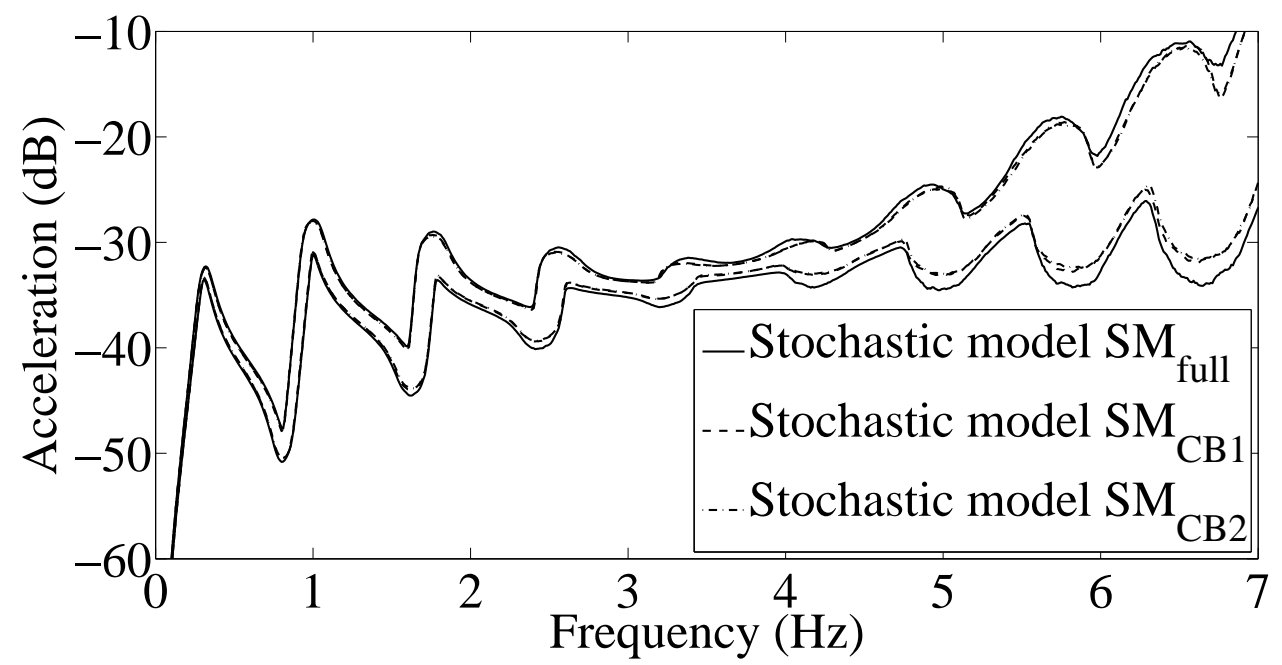

Fig. 3 Comparison of three stochastic models: Frequency response in acceleration for point $\mathrm{P}_{\mathrm{obs}, 2}$.

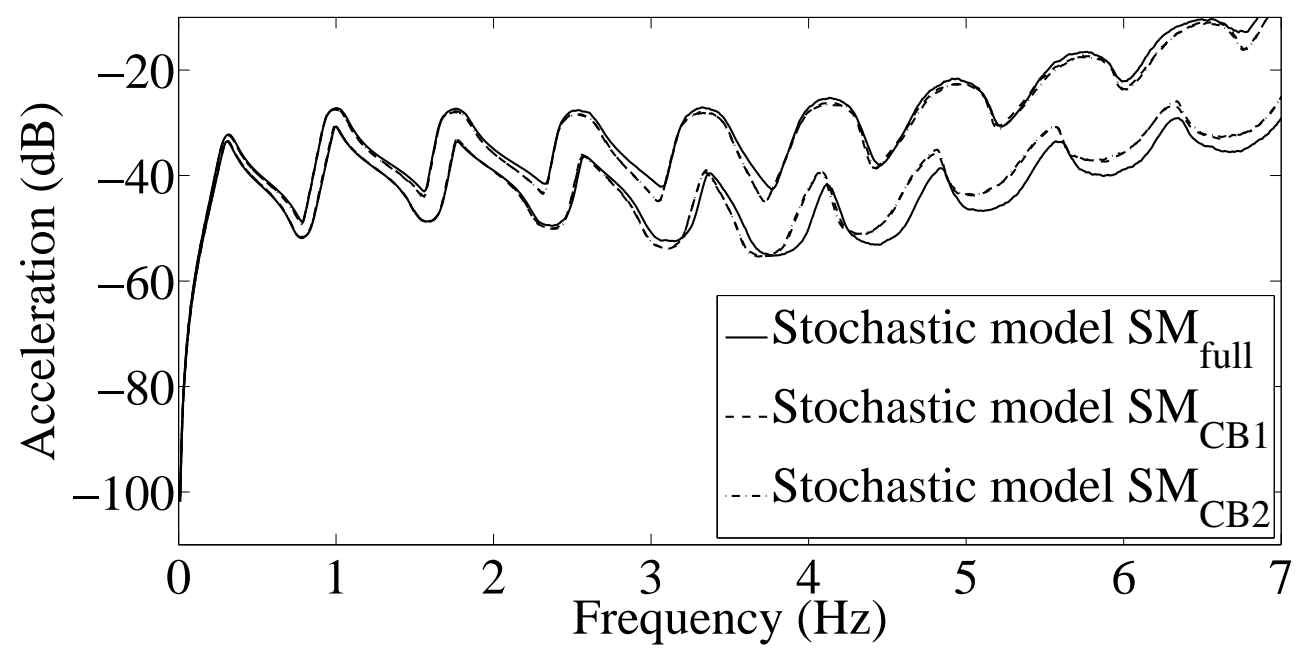

Fig. 4 Comparison of three stochastic models: Frequency response in acceleration for point $\mathrm{P}_{\mathrm{obs}, 3}$.

It can be observed that the statistical envelopes get wider as the frequency increases, especially for the response in the interface node, Fig. 3. The three figures present similar results, except for a region around 3.7Hz, where Fig. 3 presents a small statistical envelope.

The bottom line is that the $\mathrm{SM}_{\mathrm{CB} 2}$ behavior is very similar to $\mathrm{SM}_{\text {full }}$ and $\mathrm{SM}_{\mathrm{CB} 1}$, using the same values for dispersion parameter. This result indicates that the strategy proposed in the present paper is consistent with the other strategies. However, the new strategy allows more parameters to control uncertainties.

Next section will explore the results of the new stochastic model for different levels of uncertainties, which allows the control of uncertainties for each operator, each substructure and each inner or interface DOF.

4.3 Random response of stochastic model $\mathrm{SM}_{C B 2}$

4.3.1 Mass versus damping versus stiffness

i- Case study 1: mass uncertainty, Table 1. 


\begin{tabular}{|l|c|c|c|c|}
\hline & DP-inner & DP-interface & BHA-inner & BHA-interface \\
\hline Mass & $\delta_{M, \mathrm{I}, 1}=0.1$ & $\delta_{M, \Gamma, 1}=0.1$ & $\delta_{M, \mathrm{I}, 2}=0.1$ & $\delta_{M, \Gamma, 2}=0.1$ \\
\hline Damping & $\delta_{C, \mathrm{I}, 1}=0$ & $\delta_{C, \Gamma, 1}=0$ & $\delta_{C, \mathrm{I}, 2}=0$ & $\delta_{C, \Gamma, 2}=0$ \\
\hline Stiffness & $\delta_{K, \mathrm{I}, 1}=0$ & $\delta_{K, \Gamma, 1}=0$ & $\delta_{K, \mathrm{I}, 2}=0$ & $\delta_{K, \Gamma, 2}=0$ \\
\hline
\end{tabular}

Table 1 Case study 1: Values of the dispersion parameters.

ii- Case study 2: damping uncertainty, Table 2.

\begin{tabular}{|l|c|c|c|c|}
\hline & DP-inner & DP-interface & BHA-inner & BHA-interface \\
\hline Mass & $\delta_{M, \mathrm{I}, 1}=0$ & $\delta_{M, \Gamma, 1}=0$ & $\delta_{M, \mathrm{I}, 2}=0$ & $\delta_{M, \Gamma, 2}=0$ \\
\hline Damping & $\delta_{C, \mathrm{I}, 1}=0.1$ & $\delta_{C, \Gamma, 1}=0.1$ & $\delta_{C, \mathrm{I}, 2}=0.1$ & $\delta_{C, \Gamma, 2}=0.1$ \\
\hline Stiffness & $\delta_{K, \mathrm{I}, 1}=0$ & $\delta_{K, \Gamma, 1}=0$ & $\delta_{K, \mathrm{I}, 2}=0$ & $\delta_{K, \Gamma, 2}=0$ \\
\hline
\end{tabular}

Table 2 Case study 2: Values of the dispersion parameters.

iii- Case study 3: stiffness uncertainty, Table 3.

\begin{tabular}{|l|c|c|c|c|}
\hline & DP-inner & DP-interface & BHA-inner & BHA-interface \\
\hline Mass & $\delta_{M, \mathrm{I}, 1}=0$ & $\delta_{M, \Gamma, 1}=0$ & $\delta_{M, \mathrm{I}, 2}=0$ & $\delta_{M, \Gamma, 2}=0$ \\
\hline Damping & $\delta_{C, \mathrm{I}, 1}=0$ & $\delta_{C, \Gamma, 1}=0$ & $\delta_{C, \mathrm{I}, 2}=0$ & $\delta_{C, \Gamma, 2}=0$ \\
\hline Stiffness & $\delta_{K, \mathrm{I}, 1}=0.1$ & $\delta_{K, \Gamma, 1}=0.1$ & $\delta_{K, \mathrm{I}, 2}=0.1$ & $\delta_{K, \Gamma, 2}=0.1$ \\
\hline
\end{tabular}

Table 3 Case study 3: Values of the dispersion parameters.

Figures 5, 6 and 7 show the random responses comparing uncertainties in the mass, damping and stiffness matrices. The results are very similar for uncertain mass and stiffness matrices, except at very low frequencies, where stiffness uncertainties are predominant. Also, overall, the statistical envelopes increase with the frequency.

On the other hand, the cited figures show that the sensitivity of the response for an uncertain damping model is very low (very thin statistical envelopes). In other words, the system is robust to damping model uncertainties, considering the dispersion parameters used.

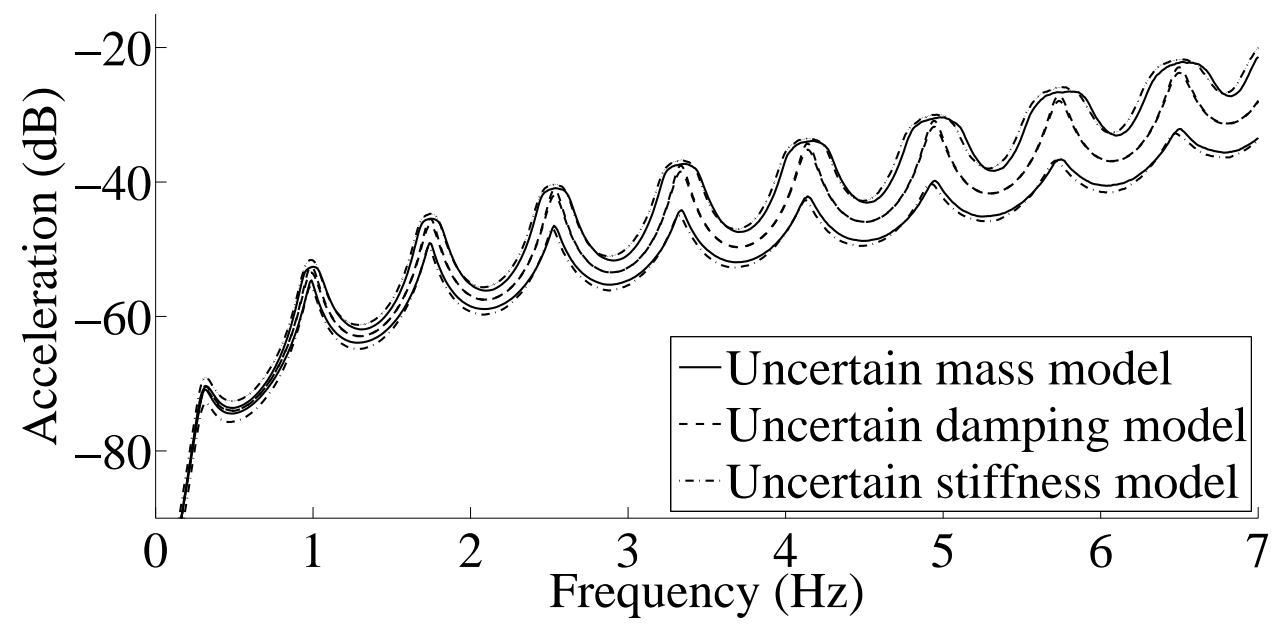

Fig. 5 Case study 1, 2 and 3: Frequency response in acceleration for point $\mathrm{P}_{\mathrm{obs}, 1}$. 


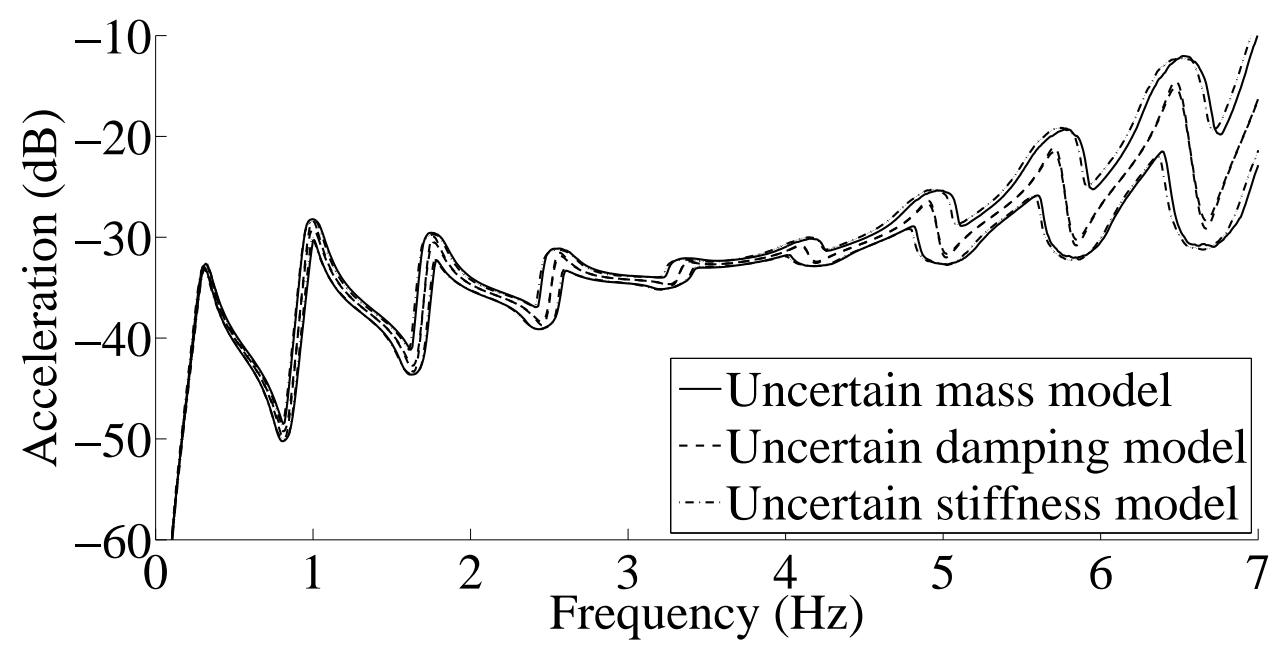

Fig. 6 Case study 1, 2 and 3: Frequency response in acceleration for point $\mathrm{P}_{\mathrm{obs}, 2}$.

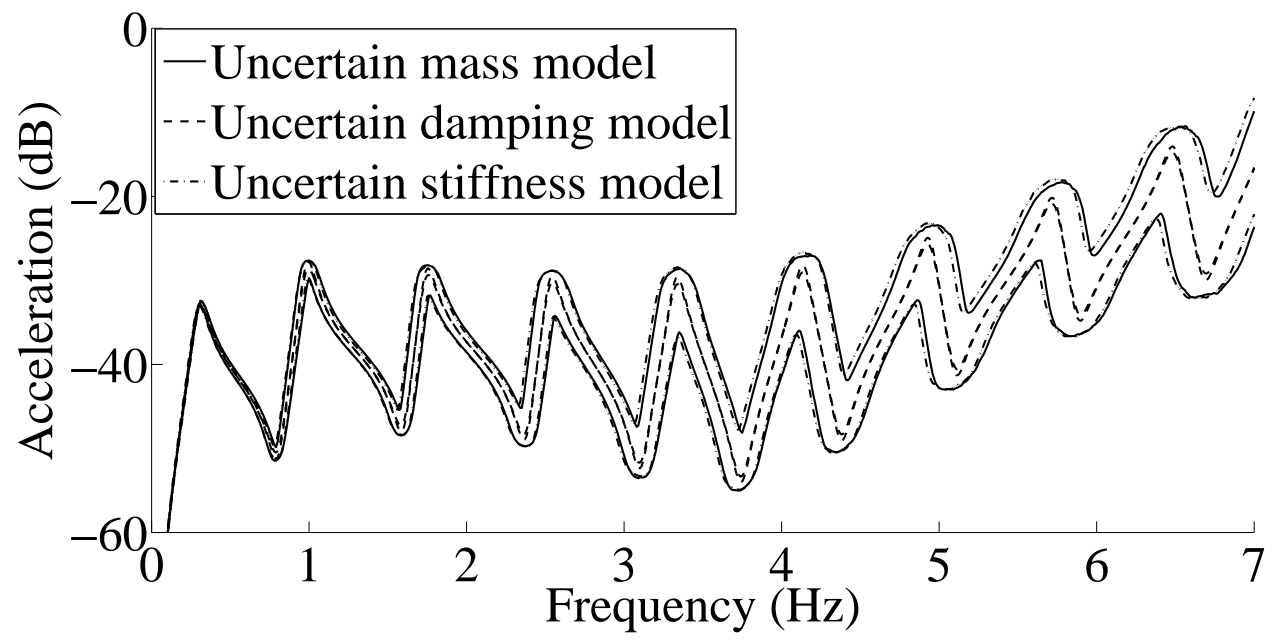

Fig. 7 Case study 1, 2 and 3: Frequency response in acceleration for point $\mathrm{P}_{\mathrm{obs}, 3}$.

\subsubsection{DP versus BHA}

i- Case study 4: DP uncertainty, Table 4.

\begin{tabular}{|l|c|c|c|c|}
\hline & DP-inner & DP-interface & BHA-inner & BHA-interface \\
\hline Mass & $\delta_{M, \mathrm{I}, 1}=0.1$ & $\delta_{M, \Gamma, 1}=0.1$ & $\delta_{M, \mathrm{I}, 2}=0$ & $\delta_{M, \Gamma, 2}=0$ \\
\hline Damping & $\delta_{C, \mathrm{I}, 1}=0.1$ & $\delta_{C, \Gamma, 1}=0.1$ & $\delta_{C, \mathrm{I}, 2}=0$ & $\delta_{C, \Gamma, 2}=0$ \\
\hline Stiffness & $\delta_{K, \mathrm{I}, 1}=0.1$ & $\delta_{K, \Gamma, 1}=0.1$ & $\delta_{K, \mathrm{I}, 2}=0$ & $\delta_{K, \Gamma, 2}=0$ \\
\hline
\end{tabular}

Table 4 Case study 4: Values of the dispersion parameters.

ii- Case study 5: BHA uncertainty, Table 5.

Figures 8, 9 and 10 show the random responses comparing uncertainties in the DP and in the BHA. The statistical envelopes for uncertain DP increase significantly when frequency increases, except around $3.7 \mathrm{~Hz}$, where they become thinner. 


\begin{tabular}{|l|c|c|c|c|}
\hline & DP-inner & DP-interface & BHA-inner & BHA-interface \\
\hline Mass & $\delta_{M, \mathrm{I}, 1}=0$ & $\delta_{M, \Gamma, 1}=0$ & $\delta_{M, \mathrm{I}, 2}=0.1$ & $\delta_{M, \Gamma, 2}=0.1$ \\
\hline Damping & $\delta_{C, \mathrm{I}, 1}=0$ & $\delta_{C, \Gamma, 1}=0$ & $\delta_{C, \mathrm{I}, 2}=0.1$ & $\delta_{C, \Gamma, 2}=0.1$ \\
\hline Stiffness & $\delta_{K, \mathrm{I}, 1}=0$ & $\delta_{K, \Gamma, 1}=0$ & $\delta_{K, \mathrm{I}, 2}=0.1$ & $\delta_{K, \Gamma, 2}=0.1$ \\
\hline
\end{tabular}

Table 5 Case study 5: Values of the dispersion parameters.

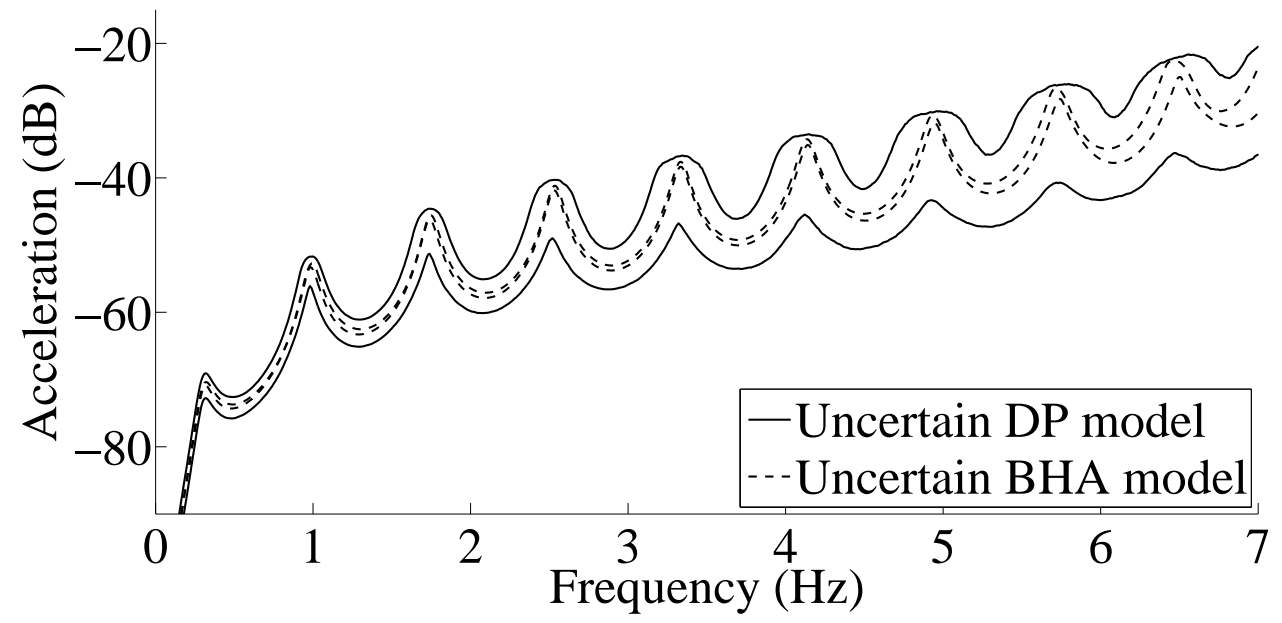

Fig. 8 Case study 4 and 5: Frequency response in acceleration for point $P_{o b s, 1}$.

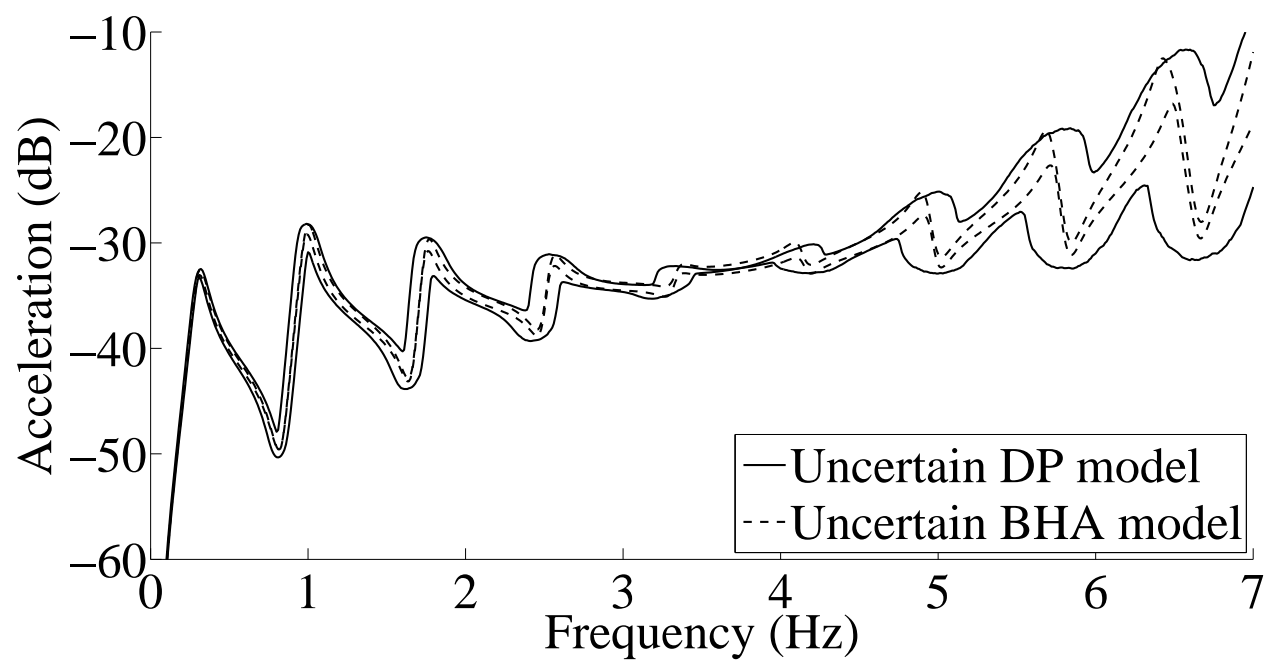

Fig. 9 Case study 4 and 5: Frequency response in acceleration for point $\mathrm{P}_{\mathrm{obs}, 2}$.

For uncertain BHA, the envelopes increase more significantly from $5 \mathrm{~Hz}$ until $7 \mathrm{~Hz}$, but they are much thinner than the response of the system for an uncertain DP. It can be concluded that the DP uncertainties affects more the response of the system for the frequency range analyzed. This is due to the DP high structural flexibility, or low stiffness, compared to BHA stiffness.

\subsubsection{Inner DOFs versus interface DOFS}

i- Case study 6: Inner DOFs uncertainty, Table 6.

ii- Case study 7: Interface DOFs uncertainty, Table 7. 


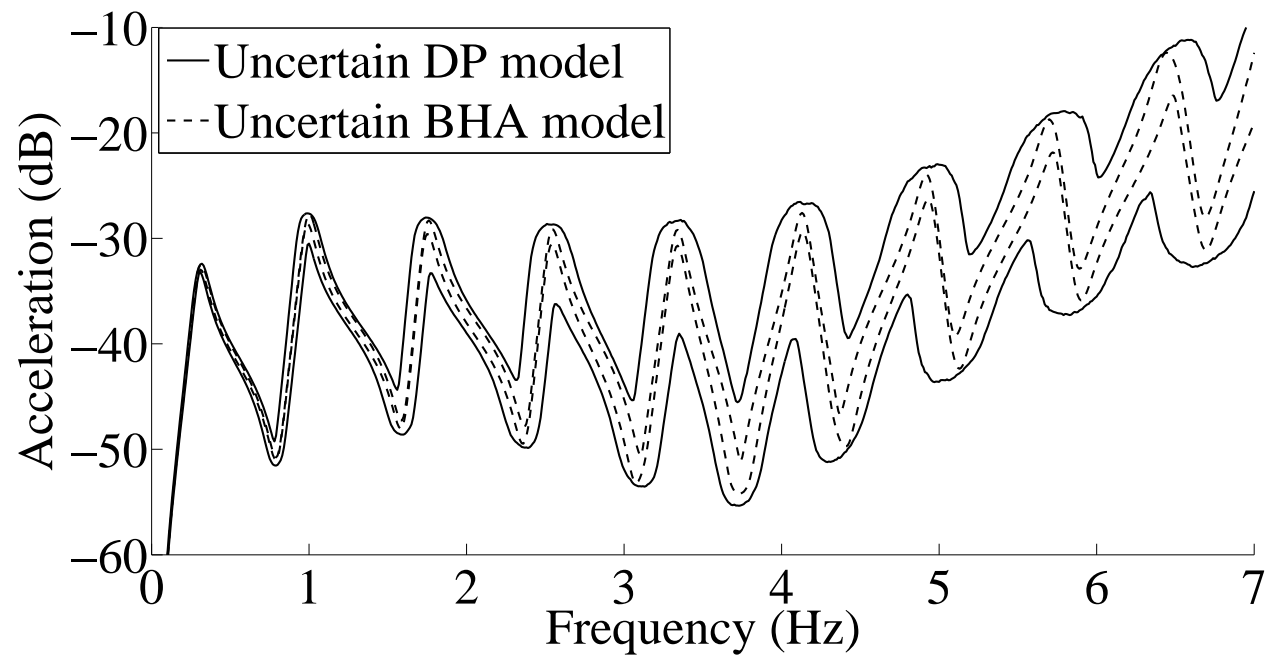

Fig. 10 Case study 4 and 5: Frequency response in acceleration for point $\mathrm{P}_{\mathrm{obs}, 3}$.

\begin{tabular}{|l|c|c|c|c|}
\hline & DP-inner & DP-interface & BHA-inner & BHA-interface \\
\hline Mass & $\delta_{M, \mathrm{I}, 1}=0.1$ & $\delta_{M, \Gamma, 1}=0$ & $\delta_{M, \mathrm{I}, 2}=0.1$ & $\delta_{M, \Gamma, 2}=0$ \\
\hline Damping & $\delta_{C, \mathrm{I}, 1}=0.1$ & $\delta_{C, \Gamma, 1}=0$ & $\delta_{C, \mathrm{I}, 2}=0.1$ & $\delta_{C, \Gamma, 2}=0$ \\
\hline Stiffness & $\delta_{K, \mathrm{I}, 1}=0.1$ & $\delta_{K, \Gamma, 1}=0$ & $\delta_{K, \mathrm{I}, 2}=0.1$ & $\delta_{K, \Gamma, 2}=0$ \\
\hline
\end{tabular}

Table 6 Case study 6: Values of the dispersion parameters.

\begin{tabular}{|l|c|c|c|c|}
\hline & DP-inner & DP-interface & BHA-inner & BHA-interface \\
\hline Mass & $\delta_{M, \mathrm{I}, 1}=0$ & $\delta_{M, \Gamma, 1}=0.1$ & $\delta_{M, \mathrm{I}, 2}=0$ & $\delta_{M, \Gamma, 2}=0.1$ \\
\hline Damping & $\delta_{C, \mathrm{I}, 1}=0$ & $\delta_{C, \Gamma, 1}=0.1$ & $\delta_{C, \mathrm{I}, 2}=0$ & $\delta_{C, \Gamma, 2}=0.1$ \\
\hline Stiffness & $\delta_{K, \mathrm{I}, 1}=0$ & $\delta_{K, \Gamma, 1}=0.1$ & $\delta_{K, \mathrm{I}, 2}=0$ & $\delta_{K, \Gamma, 2}=0.1$ \\
\hline
\end{tabular}

Table 7 Case study 7: Values of the dispersion parameters.

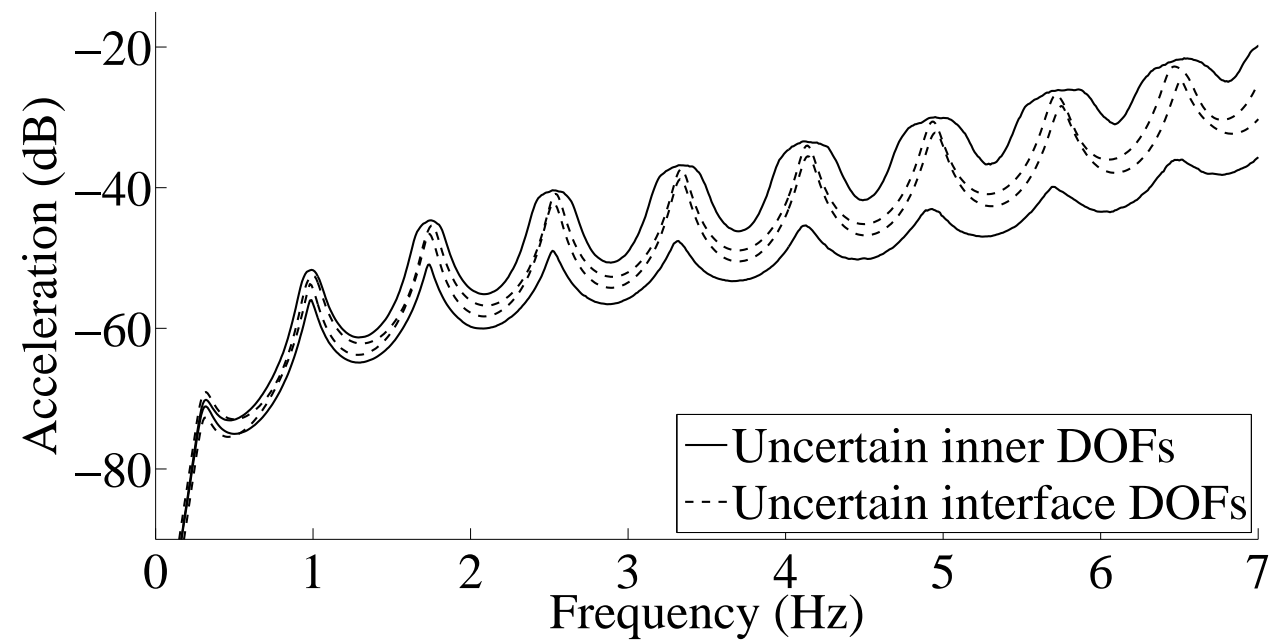

Fig. 11 Case study 6 and 7: Frequency response in acceleration for point $P_{o b s, 1}$.

Figures 11, 12 and 13 show the random responses comparing inner and interface uncertainties. Both statistical envelopes increase when frequency increases, except in the region around $3.7 \mathrm{~Hz}$ for $\mathrm{P}_{\mathrm{obs}, 2}$. However, 


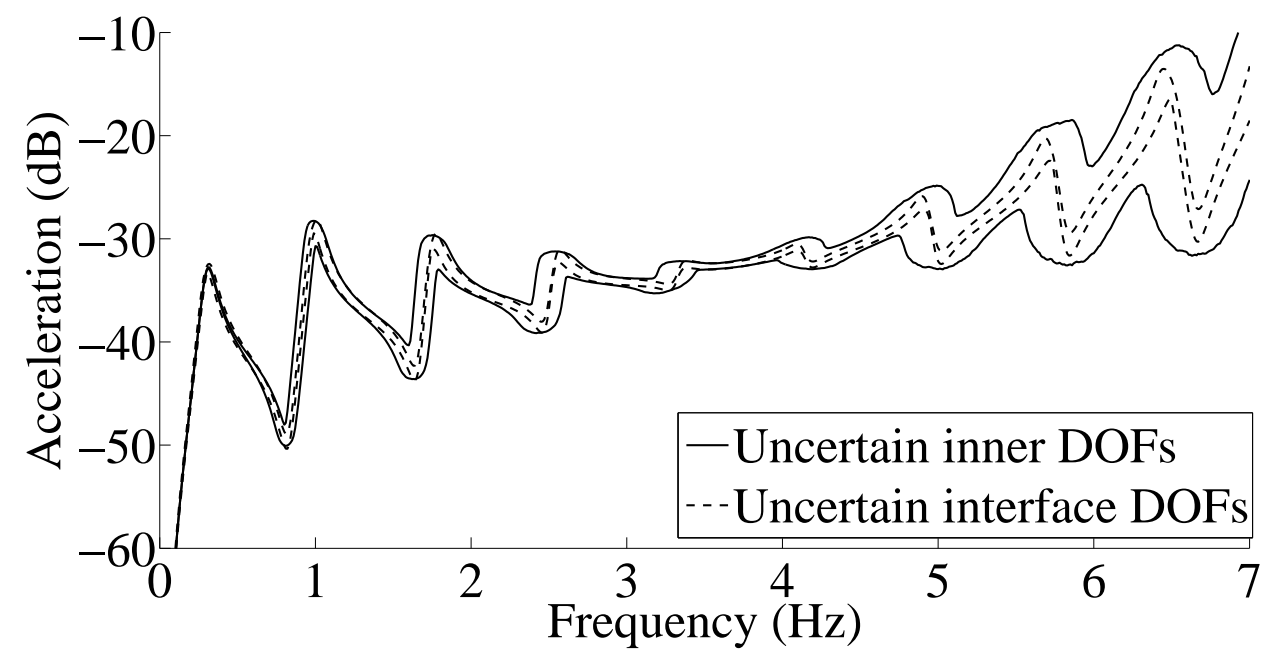

Fig. 12 Case study 6 and 7: Frequency response in acceleration for point $P_{o b s, 2}$.

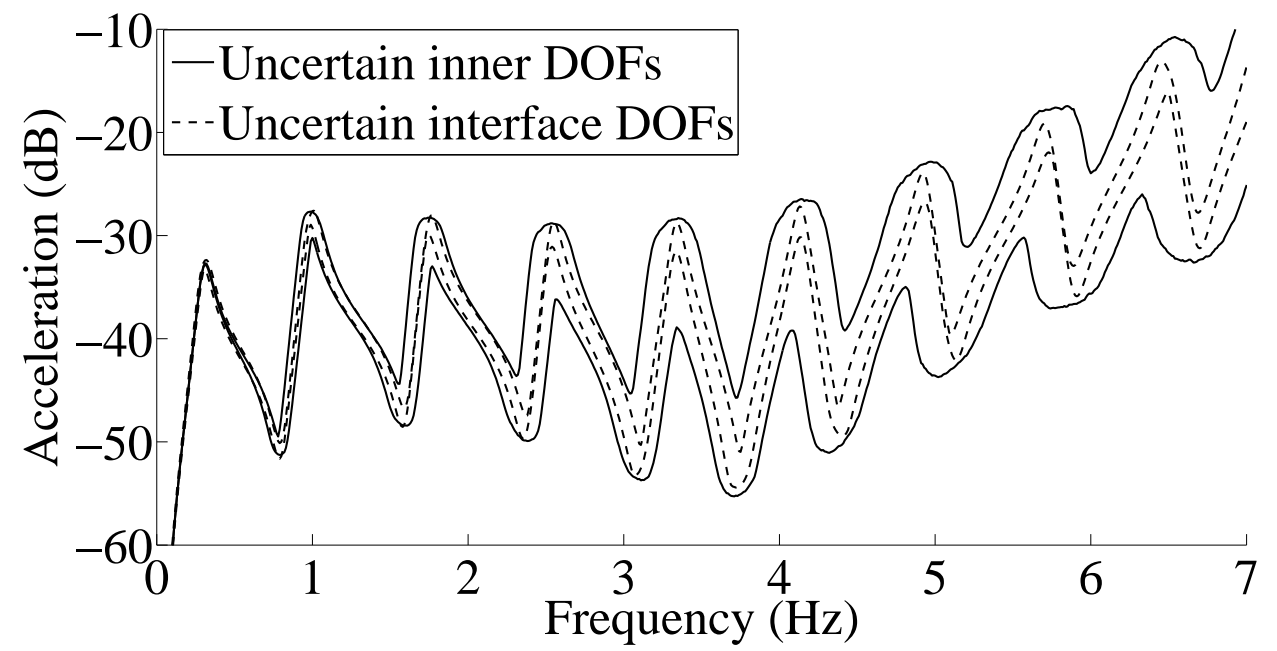

Fig. 13 Case study 6 and 7: Frequency response in acceleration for point $P_{o b s, 3}$.

the statistical envelopes for uncertain interface DOFs are much thinner comparing to the statistical envelopes for uncertain inner DOFs. In the present analysis there is only $1 \mathrm{DOF}$ in the interface, and the response is robust to uncertainties in this interface DOF, although it has a clear impact in the random response of the system.

\section{Concluding Remarks}

This paper dealt with modeling uncertainties in the substructures and interfaces of a dynamical system. The strategy proposed was based on the Craig-Bampton substructuring method and the use of the nonparametric probabilistic approach for the global modeling of uncertainties in each substructures. The random vibrations of the torsional drill-string were analyzed, where the column is divided in two substructures (1) Drill-Pipe (DP) and (2)Bottom-Hole-Assembly (BHA).

It was reported that (1) the full nonparametric probabilistic approach, (2) the existing nonparametric probabilistic approach together with the Craig-Bampton substructuring method, and (3) the new strategy proposed 
in this paper give similar results for the same level of uncertainty. Therefore, these approaches are consistent, and the new strategy allows, for each substructure, to construct separated models of uncertainties for the inner and the interface DOFs. Thus, it permits to control separately the levels of fluctuation induced by these two sources of uncertainties. From experimental data, it is possible to identify the dispersion parameters according to the operators level and according to the inner or interface DOFs.

Concerning the response of the system analyzed, it can be highlighted that the random torsional vibration of the drill-string is (1) little affected by uncertainties in the damping operator, (2) more affected by uncertainties in the DP substructure, compared to uncertainties in the BHA, (3) similarly affected by uncertainties in the mass and the stiffness operators, and (4) little affected by uncertainties in the interface DOF.

Acknowledgements The authors are grateful to the financial support of the Brazilian agencies CAPES, CNPq, and FAPERJ.

\section{References}

1. Chebli H and Soize C (2004) Experimental validation of a nonparametric probabilistic model of non homogeneous uncertainties for dynamical systems. Journal of the Acoustical Society of America Vol: 115 (2) 697-705.

2. Chen C, Duhamel D, and Soize C (2006) Probabilistic approach for model and data uncertainties and its experimental identification in structural dynamics: case of composite sandwich panels. Journal of Sound and Vibration Vol: 294 (1-2) 64-81.

3. Chin WC (1994) Wave Propagation in Petroleum Engineering: Modern Applications to Drillstring Vibrations, Gulf Publishing.

4. Craig R and Bampton M (1968) Coupling of Substructures for Dynamic Analysis. AIAA Journal Vol: 6 (7) 1313-1319 .

5. Duchereau J and Soize C (2006) Transient dynamics in structures with nonhomogeneous uncertainties induced by complex joints. Mechanical Systems and Signal Processing Vol: 20 (4) 854-867.

6. Durand J-F, Soize C, and Gagliardini L (2008) Structural-acoustic modeling of automotive vehicles in presence of uncertainties and experimental identification and validation. Journal of the Acoustical Society of America Vol: 124 (3) 1513-1525.

7. Fernandez C, Soize C, and Gagliardini L (2010) Sound-insulation layer modelling in car computational vibroacoustics in the medium-frequency range. Acta Acustica united with Acustica (AAUWA) Vol: 96 (3) 437-444.

8. Ghanem RG and Spanos PD (1991) Stochastic Finite Elements: A Spectral Approach. Dover Publications Inc.

9. Jansen JD (1993) Nonlinear dynamics of oilwell drillstrings. PhD thesis, Technische Universiteit Delft.

10. Jaynes ET (2003) Probability Theory: The Logic of Science. Cambridge University Press.

11. Khulief YA, Al-Naser H (2005) Finite element dynamic analysis of drillstrings. Finite Elements in Analysis and Design Vol: 41 1270-1288

12. Mehta ML (1991) Random Matrices. Revised and Enlarged Second Edition. Academic Press.

13. Mignolet M, Soize C and Avalos J (2013) Nonparametric stochastic modeling of structures with uncertain boundary conditions/coupling between substructures. AIAA Journal Vol: 51 (6) pp. 1296-1308.

14. Morand HPJ and Ohayon R (1979) Substructure variational analysis for the vibrations of coupled fluid-structure systems. Int. J. Num. Meth. Eng. Voo: 14 (5),741-755.

15. Ritto TG, Soize C and Sampaio R (2009) Non-linear dynamics of a drill-string with uncertain model of the bit-rock interaction. International Journal of Non-Linear Mechanics Vol: 44 (8) pp. 865-876.

16. Ritto TG, Soize C and Sampaio R (2010) Robust optimization of the rate of penetration of a drill-string using a stochastic nonlinear dynamical model. Computational Mechanics Vol: 45 (5) pp. 415-427.

17. Ritto TG, Soize C, and Sampaio R (2010) Probabilistic model identification of the bit rock-interaction-model uncertainties in nonlinear dynamics of a drill-string. Mechanics Research Communications, Vol. 37 pp. 584-589.

18. Ritto TG, Sampaio R (2012) Stochastic drill-string dynamics with uncertainty on the imposed speed and on the bit-rock interaction parameters. International Journal for Uncertainty Quantification Vol: 2 (2), 111-124 .

19. Ritto TG, Escalante MR, Sampaio R, Rosales MB (2013) Drill-string horizontal dynamics with uncertainty on the frictional force. Journal of Sound and Vibration Vol: 332 (1), 145-153.

20. Ritto TG and Sampaio R (2013) Measuring the efficiency of vertical drill-strings: A vibration perspective. Mechanics Research Communications Vol. 52 pp. 32-39.

21. Rubinstein RY (2007) Simulation and the Monte Carlo Method. Series in Probability and Statistics. John Wiley and Sons, New Jersey, USA, 2nd edition.

22. Sampaio R, Piovan MT and Lozano GV (2007) Coupled axial/torsional vibrations of drilling-strings by mean of nonlinear model. Mechanics Research Comunications, Vol: 34 (5-6) pp. 497-502.

23. Schueller GI (2006) Developments in stochastic structural mechanics. Archive of Applied Mechanics Vol: 75 (10-12) pp. 755-773.

24. Schueller GI (2007) On the treatment of uncertainties in structural mechanics and analysis. Computers and Structures Vol: $85(5-6)$ pp. $235-243$.

25. Soize C (2000) A nonparametric model of random uncertainties for reduced matrix models in structural dynamics. Probabilistic Engineering Mechanics Vol: 15 (3) pp. 277-294.

26. Soize C and Chebli H (2003) Random uncertainties model in dynamic substructuring using a nonparametric probabilistic model. Journal of Engineering Mechanics Vol: 129 (24) pp. 449-457.

27. Soize C (2005) Random matrix theory for modeling uncertainties in computational mechanics. Computer Methods in Applied Mechanics and Engineering, Elsevier Vol: 194 (12-16), pp.1333-1366. 
28. Soize C, Capiez-Lernout E, Durand J-F, Fernandez C, and Gagliardini L (2008) Probabilistic model identification of uncertainties in computational models for dynamical systems and experimental validation. Computer Methods in Applied Mechanics and Engineering Vol: 198 pp. 150-163.

29. Spanos PD, Chevallier AM, and Politis NP (2002) Nonlinear stochastic drill-string vibrations. Journal of Vibration and Acoustics, Transactions of the ASME, Vol. 124 (4) pp. 512-518.

30. Spanos PD, Chevalier AM, Politis NP, and Payne ML (2003) Oil and gas well drilling: A vibrations perspective. The Shock and Vibration Digest Vol: 35(2) pp.85-103.

31. Spanos PD, Politis NP, Esteva M, and Payne M (2009) Drillstring vibrations. Advanced Drilling and Well Technology (Society of Petroleum Engineers), pp. 117-156.

32. Tucker RW and Wang C (1999) An integrated model for drill-string dynamics. Journal of Sound and Vibration Vol. 224 (1) pp. 123-165. 